\title{
Empirical Study on the Relationship between Financial Development and Urban and Rural Residents' Income Gap in Guangdong Province
}

\author{
Jianghui Tao \\ School of economics, Jinan University, Guangzhou, China \\ Email: tjhalicekitty3@163.com
}

How to cite this paper: Tao, J. H. (2020). Empirical Study on the Relationship between Financial Development and Urban and Rural Residents' Income Gap in Guangdong Province. American Journal of Industrial and Business Management, 10, 219-231.

https://doi.org/10.4236/ajibm.2020.102014

Received: January 6, 2020

Accepted: February 2, 2020

Published: February 5, 2020

Copyright $\odot 2020$ by author(s) and Scientific Research Publishing Inc. This work is licensed under the Creative Commons Attribution International License (CC BY 4.0).

http://creativecommons.org/licenses/by/4.0/

(c) (i) Open Access

\begin{abstract}
To explore the mutual relationship between financial development and the income gap in urban and rural residents, this paper uses the Guangdong province's time series data since the reform and opening up for nearly 40 years, establishes the index of financial development degree and the urban and rural residents income gap, to financial development scale and development efficiency of financial development degree, with difference index to represent the urban and rural residents income gap between the rich and the poor. After the use of theoretical analysis based on the interaction mechanism between them, this essay makes an empirical analysis combined with vector auto-regressive model. The results show that the residents' income gap between urban and rural areas of Guangdong province will be expanded with the expansion of financial development, and will be narrowed with the improvement of the efficiency of financial development. Therefore, in order to realize the resource configuration optimization, promoting fair income distribution, we should optimize the financing channels, deepen the financial system and income distribution system, and realize the financial development and narrow the gap between urban and rural residents income to reach win-win situation.
\end{abstract}

\section{Keywords}

Guangdong Province, Financial Development, Urban and Rural Residents' Income Gap

\section{Introduction}

At present, China has established a financial system with banking industry as the core and insurance, securities and other industries developing together. Finan- 
cial development plays an increasingly significant role in promoting economic development, which has greatly improved people's overall living standards. However, with the rapid development of economy and finance, the income gap between urban and rural residents is becoming more and more prominent. As for Guangdong province, its economy has been developing rapidly in recent years. In 2015, the GDP of Guangdong reached 9727.78 billion yuan, accounting for $10.8 \%$ of the national GDP. However, by 2018, the disposable income ratio of urban and rural residents in Guangdong was 2.60:1, and the GDP of the nine cities in the Pearl River Delta accounted for $79.1 \%$ of the province's total ${ }^{1}$.

Based on the above background, this paper firstly analyzes the existing literature review, summarizes the research results, and theoretically analyzes the interaction mechanism and approaches between financial development and income gap. Secondly, taking Guangdong province as the research object, VAR model in econometrics is used for empirical analysis.

After theoretical analysis, we draw the conclusion that there is bidirectional influence between them. The degree of information symmetry brought by financial development, the liberalization of financial market and the innovation of financial instruments have greatly expanded the channels of investment and financing and reduced the income gap between urban and rural residents caused by the financial threshold effect. However, urban and rural residents, influenced by various subjective and objective factors, choose to influence the financial development reversely with their different investment preferences. At the same time, economic growth, an intermediate variable, plays a crucial role in the interaction between financial development and the behavior of urban and rural residents. And empirical research results show that there is strong relationship between financial development and urban-rural income gap. Finally, from the perspective of reality and with reference to the above conclusions, some policy suggestions are put forward to make the research more realistic.

\section{Literature Review}

To summarize the relevant research results of domestic and foreign scholars on financial development and income gap between urban and rural residents, the main viewpoints are as follows.

\subsection{There Is an Inverted U-Shaped Relationship between Financial Development and the Income Gap between Urban and Rural Residents}

Many scholars abroad have made in-depth studies on this relationship, which was first proposed by Greenwood and Jovanovich (1990), an economist, based on Simon Kuznets' "inverted u-shaped hypothesis". When they studied the dynamic relationship among income gap, financial development and economic growth, they found an inverted $\mathrm{u}$-shaped relationship between financial devel-

${ }^{1}$ Data source: http://www.stats.gov.cn/, Guangdong statistical yearbook. 
opment and income distribution, which can be interpreted as dynamic financial threshold effect. In the early stage of financial development, financial institutions need to provide financial services at a high cost due to the incomplete financial system, and most of these costs are transferred to financial participants. So access to financial services means paying high entry fees. In addition to maintaining the basic daily life, low-income people do not have enough surplus funds to pay the cost of entering the financial threshold, so they cannot enjoy financial services. In contrast, only a small number of high-income people who already have the advantage of wealth accumulation have enough wealth capital to invest, and their income level is further improved, thus widening the income gap between the two. In the later stage of financial development, as the financial system is gradually improved and the structure is increasingly reasonable, the threshold for entry is lowered. At the same time, after the wealth accumulation in the early stage, the low-income groups have the conditions to increase their income by using financial services, so the income gap between them and the high-income groups will gradually narrow. In addition, Townsend and Ueda (2003) improved the GJ model to study the long-term relationship between the two in developing countries from a dynamic perspective and reached the same conclusion.

Piketty (1997) and Matsuyama (2000) examined the correlation between financial development and residents' income gap from the perspectives of interest rate and credit supply. They believe that in the initial financial market, due to capital accumulation, the social credit of high-income people is much higher than that of low-income people, so they are less constrained by credit supply. In addition to the impact of information asymmetry, they are more likely to obtain loans at low cost for investment, thus widening the income gap between the two. However, with the improvement of the financial system and the reduction of investment and financing costs, low-income people can also obtain financing by enjoying financial services, thus increasing their investment returns. Finally, the problem of excessive income gap can be gradually solved. With the development of finance, the income gap is gradually narrowed from the expansion to the later, and the influence curve of supporting financial development on the income gap is "inverted U".

In the domestic research, Shen and Fang (2005) also reached the same point of view by using the data of China from 1978 to 2003, and believed that "China's income gap is large and will continue to expand for quite a long time".

\subsection{Financial Development Is Positively Correlated with Income Gap}

In recent years, with the development and improvement of finance, the problem of social inequality is increasingly serious. Therefore, many scholars have proposed that there is a positive correlation between financial development and income gap, that is, financial development will widen the income gap. Maurer and Haber (2003) argued that the deepening of financial development and the im- 
provement of market liberalization did not enable poor people and small and medium-sized enterprises to enjoy due financial services, but provided the rich with credit support channels and increased their access to high returns, thus inevitably widening the income gap of residents. Later, Philip and Asena (2004) put forward a new opinion on this phenomenon from the perspective of financial skill level. In reality, access to financing channels does not necessarily bring high returns. Because of the lack of the ability to use and manage the borrowed funds, the low-income group cannot allocate the financial resources efficiently, and may even reduce their wealth. On the other hand, the high-income group has enough funds to get good education and is better at planning investment and financial management, or it has a comparative advantage in human capital. Therefore, they can make more efficient use of borrowed funds, optimize the allocation of resources, and finally increase their real income. The disparity in financial skills caused by the difference in human capital is an important reason for the widening of the income gap. Zhang et al. (2003) mainly chose the ratio of bank credit to GDP to measure the degree of financial development, and introduced indicators such as the ratio of export trade and foreign investment to GDP as control variables. Their analysis concluded that "the development of financial intermediation promotes the widening of urban-rural income gap, while the effective financing of rural funds by financial institutions is of little significance".

\subsection{Financial Development Is Negatively Correlated with Income Gap}

Galor and Joseph (1993) proposed that, based on the information asymmetry credit market model, the continuous and sound development of financial market can make the actors in the financial system improve human capital and cross the financial threshold, so as to realize financing more conveniently and narrow the income gap. Barr (2005) proposed the concept of "micro-finance", which also reduces the poverty problem by indirectly lowering the financial threshold. He believes that more low-income groups can enjoy financial services by providing them with micro-financial services such as microcredit and financial insurance, which will not only promote financial development but also play a positive role in solving the poverty problem. Yao (2005) concluded in his research that "the scale and efficiency of financial development have a long-term equilibrium relationship with the income gap between urban and rural residents, and there is a two-way causal relationship". "The expansion of financial development widens the income gap between urban and rural residents, while the efficiency of financial development narrates the gap".

The above literature review shows that due to the differences in regions, research perspectives and research methods, the academic circle has not reached a unified conclusion on the impact of financial development and residents' income gap. In terms of research methods, foreign scholars have conducted in-depth discussions on both theoretical and empirical tests, and their research 
paths and methods are relatively mature, which have a good reference and guiding significance for the reality of various countries. In contrast, Chinese scholars mostly focus on empirical studies. According to the actual situation in China, they put forward some opinions on solving specific problems in China, which greatly enriches the research in this field. In terms of the selection of research objects, the majority of them are large national samples, and some scholars even conduct them in the world, rarely using microscopic subjects.

\section{Theoretical Mechanism}

The contradiction between financial development and income gap is the inevitable outcome of the development of market economy at a certain stage. It can be seen from the literature review above that there is a close influence between the two. Based on the above premises, this chapter focuses on the theoretical exploration of the interaction mechanism between the two.

\subsection{The Impact of Financial Development on the Income Gap between Urban and Rural Residents}

\section{1) Degree of Information Symmetry}

Information asymmetry intensifies the effect of threshold effect on the financing behavior of urban and rural residents. In real life, financial threshold mainly affects financing and then capital investment, resulting in income gap. The existence of information asymmetry increases the operating costs of financial institutions, which will be passed on to the financing parties, such as handling asset collateral and raising financing fees. This increases the cost and difficulty of loans for individuals, small, medium and micro enterprises, while for high-income groups and large enterprises, their credit ratings are higher and it is easier to realize financing and investment.

2) Level of Financial Market Liberalization

In the financial market, the government can control the flow and scale of loanable funds through monetary and fiscal policies, thus affecting the financial development. In the study of economics, the unity of opposites between the government and the market has always been the focus of our discussion. The boundary of government functions and its intervention in the market are the important factors influencing the liberalization level of the market. The greater the role of the state, the less liberalized the market. When formulating financial policies, the state usually gives preference to large state-owned holding enterprises or key enterprises above the scale and multinational enterprise groups, which occupy an important position in the national economy, especially in the period of economic depression. Excessive government intervention to weaken the regulation and control function of the market itself, making it impossible to make financial market allocation of resources to achieve the most efficient equilibrium, on the other hand, the government the policy tilt also increasing the difficulty of micro, small and medium enterprises loans, make it can't get enough financing to maintain daily operation, to the business activities and the future 
development of the enterprise has a bad influence. The decline of enterprise profitability directly causes the decline of employee income level. In contrast, the income gap between employees of different enterprises increases.

3) Financial Innovation

The intensity of financial innovation is an important symbol to measure the development stage and degree of the financial industry. Financial innovation contains many contents, including not only the innovation of financial products, but also the financial system, financial organization and other aspects. In terms of financial product innovation, it can not only make the financial investors increasingly change investment needs are met, financial market development level improved, more important is can enrich the amount and type of products, has helped increase the competition of financial institutions, so as to reduce the barriers to entry of purchase financial product, make the low-income groups to participate in the activities of financial markets and the opportunity to enjoy financial service.

In addition, the innovation of the financial market is conducive to reducing the negative effects caused by asymmetric market information, increasing the ways of capital preservation and appreciation, and improving the allocation efficiency of financial resources. Therefore, financial innovation can enable more low-income people to realize wealth appreciation through investment, which plays a positive role in narrowing the income gap of urban residents to some extent.

4) Indirect Effect of Economic Growth Effect of Financial Development on Income Gap

The development of the financial sector has a driving effect on economic growth. On the one hand, the gradual improvement of the financial market and the continuous enrichment of financial products have increased the financing and investment channels for investors, increased the function of capital accumulation, expanded the total circulation of credit capital in the financial market, and provided the necessary money supply for economic development. On the other hand, the development of finance can also promote economic development by reducing costs. The improvement of the financial system and the professional level of the service quality of financial institutions and consulting institutions not only reduces the information cost and moral hazard of financial institutions, but also helps to reduce the transaction cost of financial market participants, so as to improve the efficiency and speed of social capital allocation.

The most direct effect of economic development is to change the structure of employment and the remuneration of employees. In addition, economic development has an impact not only on the initial distribution of social wealth, but also on economic growth and national income. Through the provisions of the redistribution system, it is finally reflected in the changes in individual income, thus causing changes in the income gap of urban residents of different strata.

It can be concluded from the above analysis that, on the one hand, with the 
deepening of financial development, the degree of information symmetry and market liberalization also increases, which leads to the increase of actual credit supply and the increase of industrial and human capital input. With the improvement of financial instruments, market and institutional innovation capabilities, financial functions will continue to be improved, and capital investment and income capacity will be enhanced, which will eventually raise residents' income level and help reduce the income gap. On the other hand, financial development improves the income of urban and rural residents by promoting economic growth, and indirectly ameliorates the problem of excessive income gap. Therefore, the degree of financial development has a negative effect on the income gap of urban residents.

\subsection{The Impact of the Income Gap between Urban and Rural Residents on Financial Development}

The income gap between urban and rural residents affects financial development mainly through the behavioral choices of economic subjects. As for the low-income group, first of all, due to the relatively small income, the remaining assets that can be used for investment are not much after the basic living expenses are removed. Therefore, they are more cautious in income and expenditure, and tend to conduct conservative operation in asset investment. Secondly, limited by information asymmetry, the threshold of financial development, they do not know enough about new financial products. Finally, low-income groups account for the vast majority of the total social population. Their investment preferences and behaviors will affect the asset structure distribution, capital liquidity and borrowing scale of the entire financial market.

In terms of high income group, on the one hand, with the accumulation of wealth, the growth of the credit rating, the financial market monopoly ability to strengthen their strong investment funds can attract more financial intermediaries according to their needs to make service or research and development of financial products, the sample is likely to make the financial needs of low-income groups are neglected, distorts the real needs of the financial markets, has weakened the financial products innovation and diversification development momentum. On the other hand, although the absolute population of the high-income group is small, it controls the majority of the wealth of the society, which in a certain sense occupies the space for the low-income group to participate in financial activities. With the aggravation of the income gap, this effect will become more and more obvious, even squeezing low-income people out of the financial market, reducing the demand for financial resources, making the supply of financial resources exceed demand, distorting the development direction of the financial market and restricting the sustainable development of the financial industry.

Generally speaking, the asset investment preference of different income groups is different. A widening income gap would reduce the share of borrowing and thus hamper financial growth. In addition, the problem of excessive income gap has seriously affected the stability of people's social life, the sustainable devel- 
opment of economic development, and also has a very adverse effect on the development of finance. Therefore, income gap also has a negative effect on financial development.

\section{Empirical Analysis}

\subsection{Selection of Indicators and Analysis of Data Source}

Based on the development characteristics of Guangdong province, this paper discusses the mutual influence path factors between financial development degree and income gap of urban residents in the third chapter, and selects the following indicators to build the model.

1) Financial development efficiency (FER). Expressed as the ratio of the loan balance to the deposit balance of a financial institution at the end of the year. The larger the index, the higher the efficiency of financial development, and vice versa.

2) Financial development scale (FIR). The measure is defined as the ratio of outstanding loans to nominal GDP. The larger the index, the larger the scale of financial development, and vice versa.

3) Wealth gap index (RPD). In this paper, the ratio of per capita income of urban residents to the net income of rural residents is used as an indicator of the urban-rural wealth gap, denoted as RPD. The larger the index, the larger the gap between urban and rural wealth, and vice versa, the smaller.

The empirical research data of this paper are from Guangdong statistical yearbook, statistical data collection of new China in 55 years.

\subsection{Empirical Method}

This paper mainly USES Eviews software for empirical analysis, which is mainly divided into the following steps: first, the correlation test is conducted on the three indicators of financial development efficiency (FER), financial development scale (FIR) and wealth difference index (RPD) constructed above to preliminarily explore the correlation between variables. Secondly, the stationary test of time series data is carried out. The ADF test, which is widely used, is mainly adopted in this paper. Thirdly, the Johansen method for multi-equation model is adopted to carry out co-integration test based on VAR model.

\subsection{Empirical Process Analysis}

\section{1) Correlation test}

Firstly, the correlation of the three selected indicators is roughly confirmed and the correlation test is carried out. The results are shown in Table 1. RPD is negatively correlated with FER (correlation coefficient -0.885626 ) and positively correlated with FIR (correlation coefficient 0.623213 ). It shows that the improvement of financial development efficiency can effectively reduce the urban-rural income gap; the expansion of financial development has widened the income gap between urban and rural residents to some extent. 
Table 1. Correlation coefficient matrix between financial development and income gap.

\begin{tabular}{cccc}
\hline & RPD & FER & FIR \\
\hline RPD & 1 & -0.885626 & 0.623213 \\
FER & -0.885626 & 1 & -0.634835 \\
FIR & 0.623213 & -0.634835 & 1 \\
\hline
\end{tabular}

2) Stability test

In order to avoid the phenomenon of heteroscedasticity and "false regression", the natural logarithm of each variable is taken in the following analysis. Before modeling, ADF stationary test is conducted for the three variables. The specific test results are as follows.

The test results in Table 2 show that the original sequences of the three variables are no stationary. Since their ADF statistics are both greater than the critical value, we accept the null hypothesis that there is a unit root. After the first order difference, $\triangle \ln R P D, \triangle \ln F I R$ through inspection under the $1 \%$ significant level, $\ln F E R$ after the first difference is still not stable. But after the second-order difference, all variables reject the null hypothesis at a confidence level of $1 \%$. This indicates that the three variables selected in this paper are all second-order single integral sequences, and the VAR model can be constructed.

3) Co-integration test

Before estimating the VAR model, select the optimal lag order. In this paper, the optimal lag order should be set as 4 according to the criteria of AIC and SC, and the VAR (4) model should be built (see Table 3).

The VAR (4) model estimated by Eviews software has the following goodness of fit:

$$
R^{2}=0.8404, R^{2}=0.8756, R^{2}=0.9181
$$

It indicates that the fitting degree of the model is good.

Then, the AR root test was used in this paper to determine the stability of the estimated VAR (4). The results are shown in Figure 1 below, and the unit root module is less than 1 , indicating that the model is stable and can be used for co-integration test.

The above Table 4 and Table 5 co-integration results show that at the significance level of $5 \%$, trace statistics are larger than the critical value, rejecting the null hypothesis, indicating that there is a co-integration relationship between variables. Further tests showed that only one co-integration relationship existed between variables DLNRPD, DLNFER and DLNFIR. The co-integration equation between variables is expressed as follows:

$$
D \ln R P D=-0.149453 D \ln F E R+0.761576 D \ln F I R
$$

The results of the co-integration equation show that RPD has a long-term and stable co-integration relationship with FER and FIR. That is, the income gap is negatively correlated with the efficiency of financial development and positively 
Table 2. Unit root test results.

\begin{tabular}{cccccc}
\hline \multirow{2}{*}{ Variable } & ADF test value & \multicolumn{2}{c}{ Significance level (critical value) } & \multirow{2}{*}{ Stationary } \\
\cline { 3 - 5 } & & $1 \%$ & $5 \%$ & $10 \%$ & \\
\hline $\ln R P D$ & -1.8349 & -3.6463 & -2.9540 & -2.6158 & unstable \\
$\Delta \ln R P D$ & -4.3202 & -3.6463 & -2.9540 & -2.6158 & stable \\
$\Delta^{2} \ln R P D$ & -8.8957 & -3.6329 & -2.9484 & -2.6129 & stable \\
$\ln F E R$ & -1.3488 & -3.6210 & -2.9434 & -2.6103 & unstable \\
$\Delta \ln F E R$ & -1.3611 & -3.6999 & -2.9762 & -2.6274 & unstable \\
$\Delta^{2} \ln F E R$ & -4.3949 & -3.6999 & -2.9763 & -2.6274 & stable \\
$\ln F I R$ & -1.6972 & -3.6210 & -2.9434 & -2.6103 & unstable \\
$\Delta \ln F I R$ & -6.1100 & -3.6268 & -2.9458 & -2.6115 & stable \\
$\Delta^{2} \ln F I R$ & -12.5455 & -3.6329 & -2.9484 & -2.6129 & stable \\
\hline
\end{tabular}

Note: $\Delta$ is the first order difference, $\Delta^{2}$ is the second order difference.

Table 3. The test results of the lag order of the model.

\begin{tabular}{ccccccc}
\hline Lag & LogL & LR & FPE & AIC & SC & HQ \\
\hline 0 & 71.86561 & NA & $2.36 \mathrm{E}-06$ & -4.442942 & -4.304169 & -4.397706 \\
1 & 104.2717 & 56.44941 & $5.24 \mathrm{E}-07$ & -5.953016 & -5.397924 & -5.77207 \\
2 & 112.7725 & 13.16246 & $5.51 \mathrm{E}-07$ & -5.920807 & -4.949396 & -5.604151 \\
3 & 137.1471 & 33.02358 & $2.15 \mathrm{E}-07$ & -6.912713 & -5.524983 & -6.460348 \\
4 & 165.952 & $33.45088^{*}$ & $6.57 \mathrm{e}-08^{*}$ & $-8.190450^{*}$ & $-6.386401^{*}$ & $-7.602375^{*}$ \\
5 & 173.3234 & 7.133601 & $8.60 \mathrm{E}-08$ & -8.085378 & -5.865011 & -7.361594 \\
\hline
\end{tabular}

Note: ${ }^{*}$ is the minimum value.

\section{Inverse Roots of AR Characteristic Polynomial}

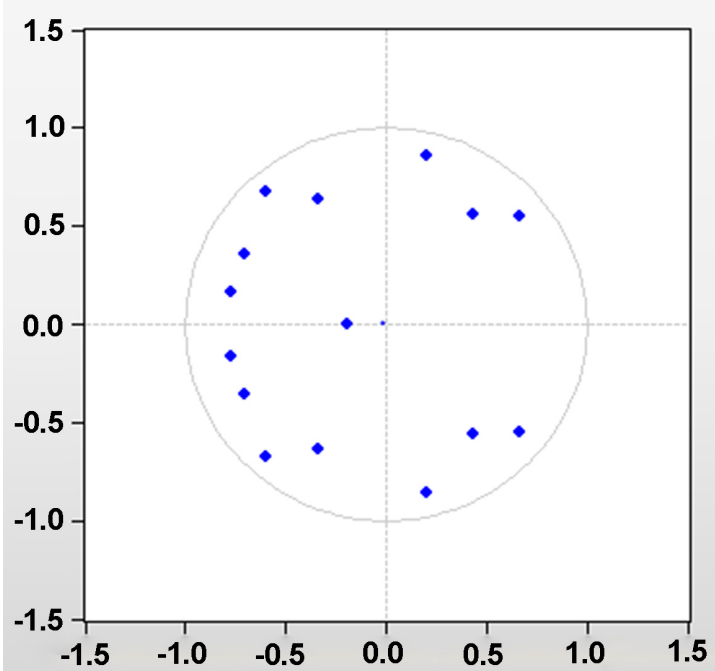

Figure 1. AR root test results. 
Table 4. Johansen co-integration test results (1).

\begin{tabular}{ccccc}
\hline Number of co-integration vectors & Eigenvalue & Trace statistic & Threshold (5\%) & P-value \\
\hline None $^{*}$ & 0.750906 & 62.63204 & 29.79707 & 0 \\
At most 1* & 0.273131 & 16.7645 & 15.49471 & 0.032 \\
At most 2* & 0.172219 & 6.237201 & 3.841466 & 0.0125 \\
\hline
\end{tabular}

Table 5. Johansen co-integration test results (2).

\begin{tabular}{ccccc}
\hline Number of co-integration vectors & Eigenvalue & Trace statistic & Threshold (5\%) & P-value \\
\hline None & 0.750906 & 45.86755 & 21.13162 & 0 \\
At most 1 & 0.273131 & 10.52729 & 14.2646 & 0.1796 \\
At most $2^{*}$ & 0.172219 & 6.237201 & 3.841466 & 0.0125 \\
\hline
\end{tabular}

correlated with the scale of financial development. The correlation analysis results above are consistent.

\subsection{Empirical Research Results}

According to the above VAR model construction and empirical test analysis, it can be seen that there is a long-term relationship between the financial development degree and the income gap of urban residents. Specific conclusions are as follows.

According to the correlation analysis results, the correlation coefficients of RPD, FER and FIR are -0.89 and 0.62 , respectively, indicating that the income gap between urban and rural residents changes in the opposite direction to the efficiency of financial development and in the same direction to the scale of financial development. The results of Johansen co-integration test are similar to the results of correlation test. Furthermore, among the two indicators, the financial development efficiency (FER) is more closely related to the income gap between urban and rural residents in Guangdong, followed by the financial development scale (FIR).

\section{Conclusions and Policy Recommendations}

This paper uses the vector autoregressive model to explore the interaction between financial development and the income gap between urban and rural residents. The results of this paper show that the income gap between urban and rural residents in Guangdong will expand with the expansion of financial development and will narrow with the improvement of financial development efficiency. Accordingly, this paper puts forward the following two suggestions.

\subsection{Optimize Financing Channels, Improve the Financial System and Improve the Efficiency of Financial Development}

First of all, lower barriers to access to financial markets, such as simplifying the procedures for ordinary shareholders to open an account, reducing the mini- 
mum capital threshold for people to buy financial products of financial institutions, etc. Allowing people from different strata to participate in financing and credit activities through various channels, and narrowing the income gap between urban and rural residents.

Secondly, expand investment and financing channels. Actively develop the folk lending business and microfinance institutions, enrich the types of financial products, vigorously explore the micro finance for small and medium-sized enterprise financing products, such as allowing financial institutions to better play to the financing function, improve the efficiency of capital turnover and operation quality.

Finally, we need to improve the financial system and the legal environment. Give full play to the advantages of Guangdong free trade zone and the functions of the financial center in terms of information, capital and factor allocation, and build a multi-level, multi-variety and multi-functional financial system. We will improve the legal environment for finance, establish a sound financial legal system and personal credit investigation system, give full play to the government's regulatory function, reduce the cost of capital allocation, and ensure the efficient and healthy operation of the financial market.

\subsection{Giving Full Play to Government Functions and Narrowing the Income Gap between Urban and Rural Residents}

Firstly, optimize and perfect my income distribution system. Under the principle of giving priority to efficiency and fairness, we will provide institutional guarantees for the rational distribution of income from labor, capital and other factors, make rational use of fiscal and monetary policy tools, and subsidize government expenditures, as well as timely formulate tax, interest rate, exchange rate system suitable to China's national conditions, fully realize the efficient and reasonable redistribution of social wealth, the urban and rural residents income gap will be controlled in a reasonable scope, promote social justice.

Secondly, increase financial input to promote the development of public education. More government spending on public education resources, which is beneficial to eliminate the unequal distribution of education resources region, class problem, make all levels of personnel have the right to equality by education, help to improve the knowledge level of the whole society, so as to reduce the threshold of knowledge, weakened due to differences in human capital concentration leads to high quality resources in a class does not bring the bad influence of the flow.

Thirdly, we need to deepen and improve the social security system. The government should strengthen the construction of China's social security system, improve the overall welfare level of the whole society, actively promote the innovation of pension, medical and other insurance systems, lower the threshold to participate in the insurance, so that more people can participate in the government to enjoy the benefits. In addition, we should give full play to the positive role of the social security system in solving the problem of poverty, and take 
targeted measures to alleviate poverty for different types of low-income groups.

\section{Conflicts of Interest}

The author declares no conflicts of interest regarding the publication of this paper.

\section{References}

Barr (2005). Microfinance and Financial Development. Michigan Journal of International Law, 26, 271-296.

Galor, O., \& Joseph, Z. (1993). Income Distribution and Macroeconomics. Review of Economic Studies, 60, 35-52. https://doi.org/10.2307/2297811

Greenwood, J., \& Jovanovich, B. (1990). Financial Development, Growth, and the Distribution of Income. Journal of Political Economy, 98, 1076-1107.

https://doi.org/10.1086/261720

Matsuyama, K. (2000). Endogenous Inequality. Review of Economic Studies, 67, 743-759. https://doi.org/10.1111/1467-937X.00152

Maurer, N., \& Haber, S. (2003). Bank Concentration, Related Lending and Economic Performance Evidence from Mexico. Redwood City: Stanford University Press. https://doi.org/10.2139/ssrn.641824

Philip, A., \& Asena, C. (2004). Financial Liberalization and Poverty: Channels of Influence. Working Paper No. 411, The Levy Economics Institute of Band College.

Piketty, T. (1997). The Dynamics of the Wealth Distribution and the Interest Rate with Credit Rationing. Review of Economic Studies, 64, 173-189. https://doi.org/10.2307/2971708

Shen, K. R., \& Fang, W. Q. (2005). Empirical Analysis on the Relationship between Income Gap and Financial Development in China. Paper of the 5th China Fifth International Economic Society.

Townsend, R.M., \& Ueda, K. (2003). Financial Deepening, Inequality and Growth: A Model-Based Quantitative Evaluation. The IMF Working Paper. https://doi.org/10.5089/9781451859836.001

Yao, J. (2005). Empirical Analysis of the Relationship between Financial Development and Urban-Rural Income Gap. Machine Study of Finance and Economics, No. 2, 49-59.

Zhang, Q., Liu, M. X., \& Tao, R. (2003). Financial Intermediary Growth and Urban-Rural Income Gap in China. Finance in China, No. 11, 3-21+80. 